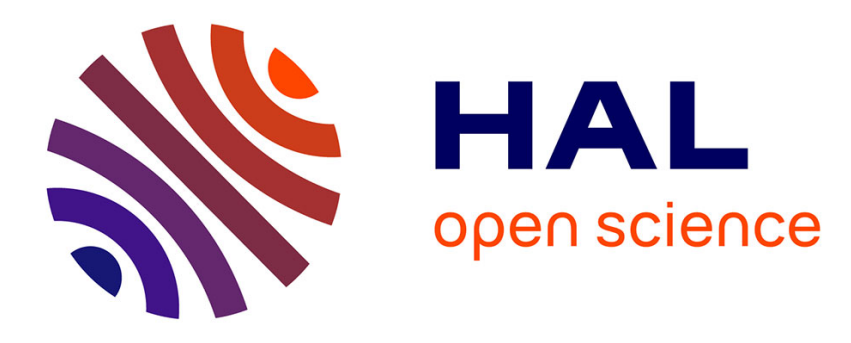

\title{
Water/oil interface in L2 phase: a small-angle X-ray scattering study
}

C. Cabos, J. Marignan

\section{To cite this version:}

C. Cabos, J. Marignan. Water/oil interface in L2 phase: a small-angle X-ray scattering study. Journal de Physique Lettres, 1985, 46 (6), pp.267-275. 10.1051/jphyslet:01985004606026700 . jpa-00232510

\section{HAL Id: jpa-00232510 https://hal.science/jpa-00232510}

Submitted on 1 Jan 1985

HAL is a multi-disciplinary open access archive for the deposit and dissemination of scientific research documents, whether they are published or not. The documents may come from teaching and research institutions in France or abroad, or from public or private research centers.
L'archive ouverte pluridisciplinaire HAL, est destinée au dépôt et à la diffusion de documents scientifiques de niveau recherche, publiés ou non, émanant des établissements d'enseignement et de recherche français ou étrangers, des laboratoires publics ou privés. 
Classification

Physics Abstracts

$82.70 \mathrm{~K}-61.10$

\title{
Water/oil interface in $L_{\mathbf{2}}$ phase : a small-angle $X$-ray scattering study
}

\author{
C. Cabos and J. Marignan \\ Groupe de Dynamique des Phases Condensées, U.S.T.L., place E. Bataillon, \\ 34060 Montpellier Cedex, France
}

(Reçu le 15 octobre 1984, révisé le 11 janvier 1985, accepté le 25 janvier 1985)

\begin{abstract}
Résumé. - Nous étudions la structure de micelles inverses du système ternaire aérosol OT- $n$ heptane-eau par diffusion centrale des rayons X. La structure de la partie polaire à l'interface eau huile est précisée. Pour un rapport d'hydratation suffisant, la partie polaire hydratée piège une goutte d'eau « libre ». Les dimensions respectives de chaque zone sont déterminées. Des mesures de rayons de giration confirment ces modèles.

Abstract. - We have studied the structure of reversed micelles in the ternary system aerosol OT- $n$ heptane-water by small-angle X-ray scattering. A structural model of the interface water/surfactant is proposed. At high water content, the film of hydrated surfactants surrounds a free water droplet. The size of the successive layers of the micelle is determined. The measurement of the radius of gyration seems to confirm our model.
\end{abstract}

\section{Introduction.}

In an organic solvent, water can be solubilized when a surfactant is added [1]. In an appropriate concentration range, the solution is made by a dispersion of water droplets surrounded by a film of surfactants in a continuous medium (the organic compound). The more common surfactant is the aerosol OT (AOT), owing to numerous industrial applications. A small-angle neutron scattering (SANS) study was presented in a previous paper [2]. It was shown that, in dilute solutions, inter-aggregate interferences can be neglected. A contrast variation allowed us to obtain the volume of the droplet, the aggregation number $n$ and the area per polar head $\sigma$.

Nevertheless, we do not know the structure of the water/surfactant interface of these inverted micelles. The experimental determination of the number of water molecules bounded to the polar heads is needed to verify some theoretical model; for instance, to obtain contributions to the free energy of ionic amphiphile-water systems [3].

The aim of this paper is to try to obtain information on the internal structure of the micelles, using small-angle X-ray scattering techniques (SAXS).

\section{Method and basic assumptions.}

A schematic representation of an AOT inverted micelle is shown in figure 1 . The aqueous core is surrounded by the polar heads of the surfactant molecules. The hydrophobic chains are in the organic solvent. 


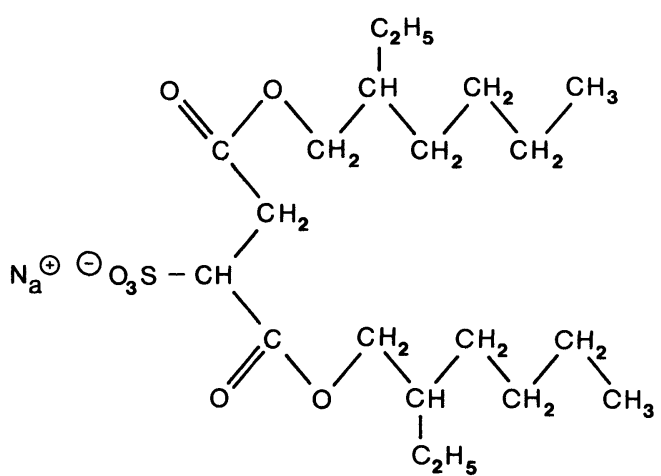

a)

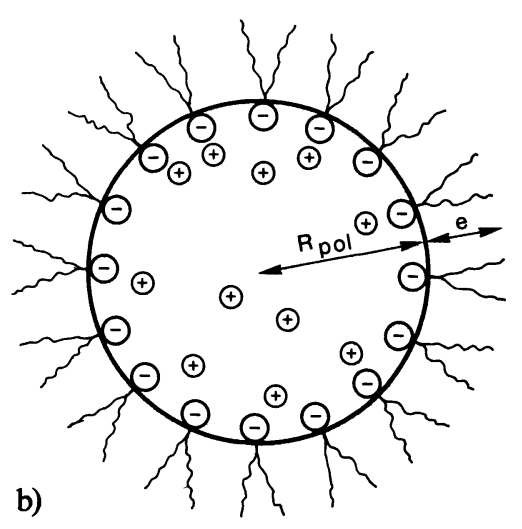

Fig. 1. - (a) The aerosol OT molecule; (b) inversed spherical micelle with an aqueous core.

We consider that, at low concentration, the $\mathrm{L}_{2}$ phase is made up of monodisperse spherical droplets. Ultracentrifugation and small-angle neutron scattering studies [2] confirm this hypothesis [14].

The electron density profile of a normal micelle is well known [4]. But the representation of the contrast profile of reversed micelles is more doubtful. Two models can be proposed.

In the first one (Fig. $2, \mathrm{~A}$ ), the electron density of the water core is constant and equal to $\overline{\rho_{\text {pol }}}$. The counterions $\mathrm{Na}^{+}$are considered to be evenly distributed in the core. $\rho_{\text {par }}$ and $\rho_{0}$ are the electron density of the paraffinic region and the solvent, respectively.

In the second model (B), one distinguishes two kinds of water : i) the water of hydratation for polar groups, and ii) free water in the droplet centre. Most counterions are bound to the polar heads [5] but some of them can be located in the free water.

The parameters $\rho_{\text {pol }}, R_{w}, l_{\text {pol }}$ (Fig. 2) are determined by the method of Reiss-Husson and Luzzati [6].

2.1 ELECTRON DENSITY OF THE INTERFACIAL REGION $\rho_{\text {pol }}$. - The integral of the scattered intensity gives the mean square value of the fluctuations of the electronic density [7] :

$$
Q=2 \pi \int_{0}^{\infty} s J_{n}(s) \mathrm{d} s=\overline{(\rho(r)-\bar{\rho})^{2}} / \bar{\rho},
$$

where $J_{n}(s)$ is the normalized scattered intensity [4] and $\bar{\rho}$ is the mean electron density of the sample (volume $V$ ).

This last equation allows us to determine $\rho_{\text {pol }}$ when the values of the other electron densities are known (as in our case).

The last formula can be written as follows (Appendix I)

$$
Q \bar{\rho}=\left(\rho_{\mathrm{w}}^{2}-\rho_{0}^{2}\right)\left(\Phi_{0}+\Phi_{\mathrm{pol}}^{*}\right)+\left(\rho_{\mathrm{pol}}+\rho_{\mathrm{w}}\right)\left(\rho_{\mathrm{pol}}^{*}-\rho_{\mathrm{w}}\right) \Phi_{\mathrm{pol}}^{*}+\left(\rho_{\mathrm{par}}^{2}-\rho_{0}^{2}\right) \Phi_{\mathrm{par}}+\rho_{0}^{2}-\bar{\rho}^{2} .
$$

2.2 RADIUS OF GYRATION MEASUREMENT. - The radius of gyration $R_{G}$ is a function of the electron density

$$
R_{G}^{2}=\int r^{2} \rho(r) \mathrm{d} r / \int \rho(r) \mathrm{d} r
$$

$R_{\mathrm{G}}$ can be calculated if one knows the profile $\rho(r)$ and the geometrical parameters of the particle (Appendix II). 


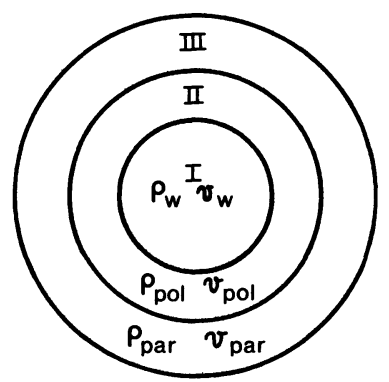

model B

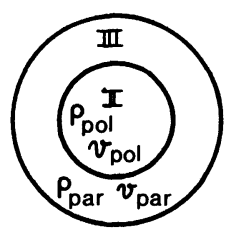

model A

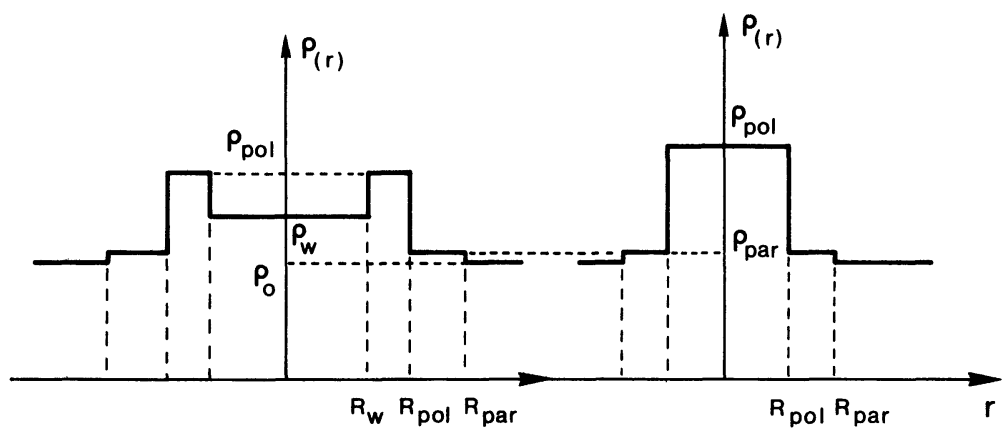

Fig. 2. - Schematic representation of a spherical micelle and its radial electron density in $n$-heptane. I : water region, its volume is $v_{\mathrm{w}}$ and its density is $\rho_{\mathrm{w}}=0.334 \mathrm{e}^{-} / \AA^{3}$. The volume of one water molecule is $29.9 \AA^{3}$ at $25^{\circ} \mathrm{C}$. II : polar region containing the polar heads, gegenions and water, its volume is $v_{\text {pol }}$ and its electron density is $\rho_{\text {pol }}$. III : paraffinic region, its volume is $v_{\text {par }}$ and its density is $\rho_{\text {par }}=0.254 \mathrm{e}^{-} / \AA^{\text {pol }}$. $S_{\mathrm{w}}$ : surface of discontinuity between $\rho_{\mathrm{w}}$ and $\rho_{\mathrm{pol}} . S_{\mathrm{pol}}$ : surface of discontinuity between $\rho_{\mathrm{pol}}$ and $\rho_{\mathrm{par}}(\sigma=$ $\left.S_{\mathrm{pol}} / n \simeq 58 \AA^{2}[2]\right) . S_{\mathrm{par}}$ : surface of discontinuity between $\rho_{\mathrm{par}}$ and $\rho_{0}\left(\rho_{0}=0.237 \mathrm{e}^{-} / \AA^{3}\right)$. Model B $: R_{\mathrm{w}}$ is the radius of the free water, $R_{\mathrm{pol}}-R_{\mathrm{w}}=l_{\mathrm{pol}}$ is the thickness of the polar region. $R_{\mathrm{par}}-R_{\mathrm{pol}}=e$ is the thickness of the surfactant coat [12].

Inversely, $R_{\mathrm{G}}$ can be deduced from SAXS. In the very small-angle region (i.e. small value of the scattering vector $s$ ) the Guinier approximation gives us [7] :

$$
R_{\mathrm{G}} \simeq 0.80 \sqrt{-\beta}
$$

where $\beta$ is the slope of the Guinier plot $\log J_{n}$ versus $(2 \theta)^{2}[11]$.

2.3 GeOMETRICAL PARAMETERS OF THE MiCELle. - At large $s$, the intensities obey Porod's law [8]. In our experimental configuration [4], if $s^{3} J_{n}(s)$ is plotted as a function of $s^{3}$, the experimental points align along a straight line with slope equal to zero. This asymptotic limit is related to the areas of the surfaces $S_{i j}$ separating two regions with different electron density $\rho_{i}$ and $\rho_{j}$

$$
\lim _{s \rightarrow \infty} s^{3} J_{n}(s)=\frac{1}{16 \pi^{2}} \sum \frac{\left(\rho_{i}-\rho_{j}\right)^{2}}{\bar{\rho}} \frac{S_{i j}}{V}=L_{\mathrm{P}} .
$$

This equation can be developed and gives (Appendix III) the value of $R_{\mathrm{w}}$ (model $\mathrm{B}$ ) or $R_{\mathrm{pol}}$ (model A). 


\section{Experimental.}

The molecular weight of the aerosol OT (sodium di-2-ethylhexylsulfosuccinate) is $444.5 \mathrm{~g}$ [2]. The water was tridistilled. The hydrocarbon solvent, obtained from Merck, is the $n$-heptane. Indeed, with such a solvent, a large amount of water can be solubilized : the molar ratio water/ OBS can reach 70. On the other hand, the boundary of the $L_{2}$ phase in the phase diagram of the ternary system AOT/water/heptane is known [9]. Water can be considered to be insoluble in this solvent.

All the measurements were performed at $25^{\circ} \mathrm{C}$. A micellar solution is characterized by the molar ratio $\omega=$ (water)/(AOT) and the water volume fraction $\Phi_{0}$. The partial specific volume of AOT is obtained with a diapason device. One finds $v_{\mathrm{AOT}}=0.8621 \mathrm{~cm}^{3} \mathrm{~g}^{-1}$ [10].

The $\omega$ values are : 8.5, 20,30,40,49.5, 66.7. The volume fraction $\Phi_{0}$ varies from $1 \%$ to $15 \%$.

$\mathrm{X}$-ray measurements were taken on a low-angle GDPA camera. The collimation system uses slits of negligible width and infinite height. The explored angular domain corresponds to $1.1 \times 10^{-3} \AA^{-1}<s<7 \times 10^{-2} \AA^{-1} . s=2 \sin \theta / \lambda$ is the scattering vector, $\lambda=1.54 \AA$ is the $\mathrm{CuK} \alpha$ wavelength and $2 \theta$ is the angle between the scattered and the incident beam.

The resolution is about $14 \AA$ and, at small $s$ range, one can measure the radius of gyration in the region of $80 \AA$.

\section{Results and discussion.}

The experimental curves are smoothly decreasing and, at large $s\left(s>3.3 \times 10^{-2} \AA^{-1}\right)$, the scattered intensities agree with Porod's law (Fig. 3). This behaviour allows us to make a good evaluation of the integral of the scattered intensity [11].

The X-ray diffraction spectra are treated using small-angle neutron scattering results [2] : the aggregation number $n$ and the volume $\left(v_{0}\right)$ of the micellar water pool.

Table I gives results obtained with samples (noted $A_{I}$ to $A_{V I}$ ), where $\omega=49.4$.

$\bar{\rho}, \Phi_{0}$ and $\Phi_{\mathrm{AOT}}$ are deduced from the concentration of the solutions. The radius of gyration $R_{\mathrm{G}}$ is evaluated from experimental curves (Guinier plot) for dilute solutions $\left(\Phi_{0}+\Phi_{\mathrm{AOT}}<6 \%\right)$ and corresponds to an extrapolation to zero concentration.

The other values of this radius $\left(R_{\mathrm{GA}}\right.$ and $\left.R_{\mathrm{GB}}\right)$ are calculated using equation (2).

Experimental results are presented in table II.

$\rho_{\text {pol }}$ is calculated from equation (1) according to model B. In model A, the polar electron density $\overline{\rho_{\text {pol }}}$ can be calculated from

$$
\overline{\rho_{\mathrm{pol}}}=\frac{\rho_{\mathrm{w}} v_{0}+\rho_{\mathrm{pol}}^{*} v_{\mathrm{pol}}^{*}}{v_{0}+v_{\mathrm{pol}}^{*}}
$$

$p$ is the number of water molecules bound to the polar heads in the region II : $p=\Delta v / 29.9 n$.

The main results depend on the $\omega$ value.

1) $\omega<20$. - Let us compare the numerical value of $\rho_{\mathrm{pol}}$ deduced from the integral of the scattered intensity and the value of $\overline{\rho_{\mathrm{pol}}}$. One can see that these two values are about the same. The radial electron density $\rho(r)$ is well represented by model A. This is emphasized by the calculated radius of gyration $R_{\mathrm{GA}}$ which gives a value very close to $R_{\mathrm{G}}$.

One can give the following interpretation : at low water content, all of the water molecules participate in the solvatation of the polar heads and the counterions $\mathrm{Na}^{+}$. This is in agreement with the behaviour of the interfacial area $\sigma$ per polar group : $\sigma$ increases if $\omega<30$ [13] and becomes constant for $\omega>30$.

2) $\omega>40$. - The main result is that $\rho_{\text {pol }}$ remains constant for all the values of $\omega$. On the other hand, the value of $\rho_{\mathrm{pol}}$ is not consistent with model A. Indeed, $\overline{\rho_{\mathrm{pol}}}$ is different from $\rho_{\mathrm{pol}}$. 
(a)

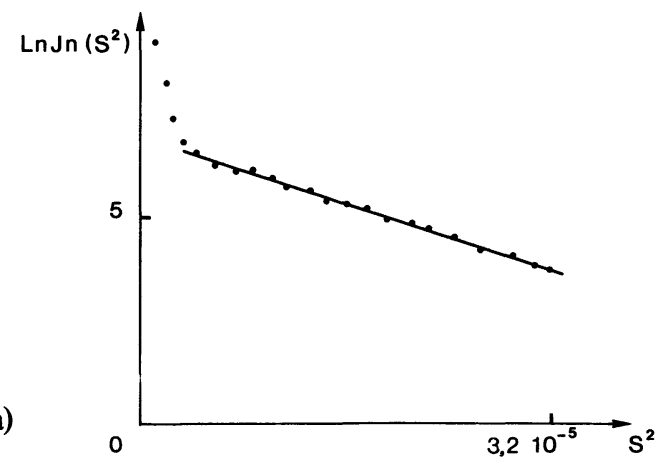

(b)

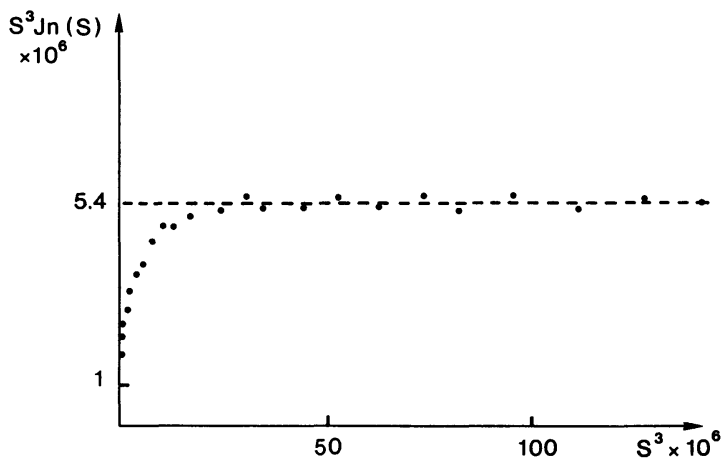

Fig. 3. - (a) Guinier plot of experimental curve : $\omega=49.4$; solution $A_{\mathrm{VI}} ; R_{\mathrm{G}}=67.5 \AA$. (b) Porod plot of experimental curve $: \omega=49.4$; solution $A_{I} ; L_{P}=5.4 \times 10^{-6}$.

Table I. - Experimental results for $\omega=49.4$. Study of solutions $\mathrm{A}_{\mathrm{I}}$ to $\mathrm{A}_{\mathrm{VI}}$ leads to the following values : $\rho_{\mathrm{pol}}=0.42 \pm 0.01 \mathrm{e}^{-} / \AA^{3}, R_{\mathrm{w}}=55 \pm 10 \AA, R_{\mathrm{G}}=66 \pm 1 \AA$.

\begin{tabular}{|c|c|c|c|c|c|c|c|c|c|c|}
\hline Sample & $\begin{array}{c}\bar{\rho} \\
\left(\mathrm{e}^{-} / \AA^{3}\right)\end{array}$ & $\Phi_{0}$ & $\Phi_{\mathrm{AOT}}$ & $\Phi_{\mathrm{w}}$ & $\begin{array}{c}10^{3} Q \\
\left(\AA^{-3}\right)\end{array}$ & $\begin{array}{c}10^{6} L_{\mathrm{P}} \\
\left(\AA^{-4}\right)\end{array}$ & $\begin{array}{c}10^{-4} Q / L_{\mathrm{P}} \\
(\AA)\end{array}$ & $\begin{array}{c}\rho_{\mathrm{pol}} \\
\left(\mathrm{e}^{-} / \AA^{3}\right)\end{array}$ & $\begin{array}{c}R_{\mathrm{w}} \\
(\AA)\end{array}$ & $\begin{array}{c}R_{\mathrm{G}} \\
(\AA)\end{array}$ \\
\hline $\mathrm{A}_{\mathrm{I}}$ & 0.2640 & 0.1714 & 0.0736 & 0.0801 & 12.9 & 5.4 & 0.24 & 0.412 & 47.5 & \\
\hline $\mathrm{A}_{\mathrm{II}}$ & 0.2498 & 0.0803 & 0.0345 & 0.0343 & 6.8 & 2.6 & 0.26 & 0.416 & 53.4 & \\
\hline $\mathrm{A}_{\mathrm{II}}$ & 0.2454 & 0.0524 & 0.0225 & 0.0218 & 4.7 & 1.7 & 0.27 & 0.420 & 52.7 & \\
\hline $\mathrm{A}_{\mathrm{IV}}$ & 0.2442 & 0.0447 & 0.0192 & 0.0209 & 4.1 & 1.5 & 0.27 & 0.419 & 59.3 & 69.7 \\
\hline $\mathrm{A}_{\mathrm{V}}$ & 0.2433 & 0.0389 & 0.0167 & 0.0180 & 3.6 & 1.35 & 0.26 & 0.422 & 56.5 & 68.5 \\
\hline $\mathrm{A}_{\mathrm{V} 1}$ & 0.2426 & 0.0345 & 0.0148 & 0.0160 & 3.2 & 1.2 & 0.26 & 0.425 & 62 & 67.5 \\
\hline
\end{tabular}


Table II. - Experimental results obtained by small-angle scattering on inverted micellar solutions AOT/water/n-heptane.

\begin{tabular}{|c|c|c|c|c|c|c|}
\hline$\omega$ & 8.5 & 20 & 30 & 40 & 49.4 & 66.7 \\
\hline$n$ & 115 & 230 & 570 & 920 & 1300 & 1820 \\
\hline $\begin{array}{c}10^{-6} v_{0} \\
\left(\AA^{3}\right)\end{array}$ & 0.027 & 0.135 & 0.51 & 1.10 & 1.87 & 3.63 \\
\hline$\rho_{\mathrm{pol}}$ & 0.57 & 0.44 & 0.41 & 0.42 & 0.42 & 0.42 \\
\hline$\overline{\rho_{\mathrm{pol}}}$ & 0.563 & 0.438 & 0.406 & 0.388 & 0.378 & 0.367 \\
\hline$R_{\mathrm{w}}$ & 0 & 0 & & 43 & 55 & 82 \\
\hline$R_{\mathrm{pol}}$ & 20 & 33 & 51 & 65 & 78 & 97 \\
\hline$l_{\mathrm{pol}}$ & & & & 22 & 23 & 15 \\
\hline$p$ & $(8.5)$ & $(20)$ & & 25 & 23 & 25 \\
\hline$R_{\mathrm{G}}$ & 17 & 27 & 40 & 55 & 66 & 80 \\
\hline$R_{\mathrm{GA}}$ & 16.8 & 26.7 & & 51 & 61 & 75 \\
\hline$R_{\mathrm{GB}}$ & & & & 54 & 65 & 80 \\
\hline
\end{tabular}

Neutron : $n$ and $v_{0}[2]$.

X-ray : for $\omega>30$, model B yields experimental values,

for $\omega<30$, this is not free water : $p=\omega$.

The uncertainties do not allow us to interpret results at $\omega=30$.

For instance, let us, consider samples with $\omega=49.4$. Table I shows that $Q$ and $L_{\mathrm{p}}$ vary linearly with the concentration. As a consequence, the ratio $Q / L_{\mathrm{p}}$ remains quasi-constant in the studied concentration range which indicates that the size of the aggregate does not vary at constant $\omega$. Our assumption seems to be valid.

Another argument is that the ratio $\Phi_{w} / \Phi_{0}$ is still constant.

$\rho_{\text {pol }}$ can be determined with a good accuracy. This allows us to obtain the free water radius $R_{\mathrm{w}}$ with an uncertainty of about $20 \%$.

This result is based upon another assumption : in the relation $v_{\mathrm{pol}}=v_{\mathrm{pol}}^{*}+\Delta v$ (Appendix I) one considers that all the $\mathrm{Na}^{+}$ions are located in region II (Fig. 2). NMR Spectroscopy [5] shows that only $28 \%$ of the $\mathrm{Na}^{+}$is dissociated from the sulfosuccinate head group. Moreover, a homogeneous distribution of the $\mathrm{Na}^{+}$in regions I and II involves a very weak variation $\Delta \rho_{\mathrm{w}}$ of the electron density of the water with respect to $\rho_{\mathrm{pol}}$.

A numerical evaluation can be given : taking the volume of $\mathrm{Na}^{+}$equal to $4 \AA^{3}$, one finds $\Delta \rho_{\mathrm{w}}=0.006 \mathrm{e}^{-} / \AA^{3}(\omega=49.4)$ which corresponds to a relative change of the contrast of the order of $8 \%$. This other approximation seems to be justified. 
Then, for $\omega \geqslant 40$, model B seems appropriate. This is true if one considers the $\rho_{\text {pol }}$ value. This is also confirmed if $R_{\mathrm{G}}$ and $R_{\mathrm{GB}}$ are compared.

The number of water molecules bound to the sulfosuccinate head is about 25 and is independent of $\omega$. As a consequence, the thickness $l_{\text {pol }}$ of region II decreases when the micelles grow.

All these results are also consistent with the behaviour of the interfacial area per polar group ( $\sigma=$ const. if $\omega>30$ ).

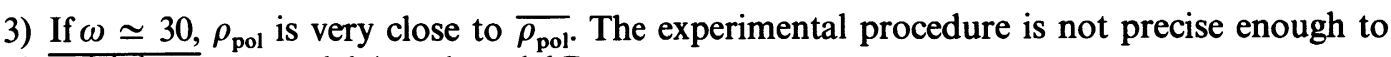
distinguish between model $\mathrm{A}$ and model $\mathrm{B}$.

\section{Conclusion.}

Both small-angle neutron and X-ray scattering allow us to obtain a more precise description of micelles. It can be shown that the water pool can be divided into two regions where the structure of the water is quite different. For a complete hydratation of the ion $\mathrm{Na}^{+}$and polar heads, about 25 water molecules are needed. This value is rather high compared with hydratation numbers. This can be first explained by the model. Indeed, the electron density profile is surely smooth and our model is a crude approximation : the polar region is the region of the micelle where the electron density is different from $\rho_{\mathrm{w}}$ and from $\rho_{\mathrm{par}}$. It must be noted that, even for normal micelles, the value of $\rho_{\text {pol }}$ deduced from X-ray results are about 0.39 for similar polar groups [4]. This gives an apparent hydratation number close to 20.

The presence of two carboxylic groups in the polar region can also explain this rather high value.

When the hydratation ratio reaches a value of 30 , free water appears in the water core.

It must be noted that the repartition of $\mathrm{Na}^{+}$ions is unknown. However, it can be shown that the main results of this study are valid whatever this repartition may be.

\section{Acknowledgments.}

This work has received financial support from PIRSEM (C.N.R.S.) under AIP no 2004.

\section{Appendix I.}

Let $v_{0}, v_{\mathrm{w}}$ and $v_{\mathrm{pol}}^{*}$ respectively be the volume of the water core, of the free water and of the polar region without hydratation in the micelle, respectively $\Phi_{0}, \Phi_{\mathrm{w}}$ and $\Phi_{\mathrm{pol}}^{*}$ are the corresponding volume fractions.

One has

$$
v_{0}=v_{\mathrm{w}}+\Delta v,
$$

where $\Delta v$ is the volume of the water of hydratation in the micelle. We also have

$$
v_{\mathrm{pol}}=v_{\mathrm{pol}}^{*}+\Delta v
$$

and

which gives

$$
\Phi_{\mathrm{w}}+\Phi_{\mathrm{pol}}=\Phi_{0}+\Phi_{\mathrm{pol}}^{*},
$$

and

$$
\left(\rho_{\mathrm{pol}}-\rho_{\mathrm{w}}\right) v_{\mathrm{pol}}=\left(\rho_{\mathrm{pol}}^{*}-\rho_{\mathrm{w}}\right) v_{\mathrm{pol}}^{*}
$$

$$
\Phi_{\mathrm{w}}=\Phi_{0}-\Phi_{\mathrm{pol}}^{*} \frac{\rho_{\mathrm{pol}}^{*}-\rho_{\mathrm{pol}}}{\rho_{\mathrm{pol}}-\rho_{\mathrm{w}}} .
$$


$Q$ can be written as follows

$$
Q \bar{\rho}=\left(\rho_{\mathrm{w}}^{2}-\rho_{0}^{2}\right) \Phi_{\mathrm{w}}+\left(\rho_{\mathrm{pol}}^{2}-\rho_{0}^{2}\right) \Phi_{\mathrm{pol}}+\left(\rho_{\mathrm{par}}^{2}-\rho_{0}^{2}\right) \Phi_{\mathrm{par}}+\rho_{0}^{2}-\bar{\rho}^{2} .
$$

This equation then leads to equation (1) using the values of $\Phi_{\mathrm{w}}$ and $\Phi_{\mathrm{pol}}$ introduced before.

\section{Appendix II.}

The calculation of the integral (2) leads to :

$$
R_{\mathrm{GA}}^{2}=\frac{3}{5} R_{\mathrm{pol}}^{2} \frac{\rho_{\mathrm{pol}}-\rho_{\mathrm{par}}+\left(\rho_{\mathrm{par}}-\rho_{0}\right)(1+b)^{5}}{\rho_{\mathrm{pol}}-\rho_{\mathrm{par}}+\left(\rho_{\mathrm{par}}-\rho_{0}\right)(1+b)^{3}},
$$

with $b=e / R_{\mathrm{pol}}$ and $e=R_{\mathrm{par}}-R_{\mathrm{pol}}$ for model A and

$$
R_{\mathrm{GB}}^{2}=\frac{3}{5} R_{\mathrm{w}}^{2} \frac{\rho_{\mathrm{w}}-\rho_{\mathrm{pol}}+\left(\rho_{\mathrm{pol}}-\rho_{\mathrm{par}}\right)(1+a)^{5}+\left(\rho_{\mathrm{par}}-\rho_{0}\right)(1+a+b)^{5}}{\rho_{\mathrm{w}}-\rho_{\mathrm{pol}}+\left(\rho_{\mathrm{pol}}-\rho_{\mathrm{par}}\right)(1+a)^{3}+\left(\rho_{\mathrm{par}}-\rho_{0}\right)(1+a+b)^{3}}
$$

with $a=l_{\mathrm{pol}} / R_{\mathrm{w}}$ and $b=e / R_{\mathrm{w}}$ for model B.

In all the cases, the length of the paraffinic chain is considered to be equal to $9 \AA$.

\section{Appendix III.}

We assume that the micelle is spherical. Then equation (3) can be developed and we obtain :

- Model B

$$
\begin{aligned}
16 \pi^{2} L_{\mathrm{p}} & =\frac{1}{\bar{\rho} V}\left[\left(\rho_{\mathrm{w}}-\rho_{\mathrm{pol}}\right)^{2} S_{\mathrm{w}}+\left(\rho_{\mathrm{pol}}-\rho_{\mathrm{par}}\right)^{2} S_{\mathrm{pol}}+\left(\rho_{\mathrm{par}}-\rho_{0}\right)^{2} S_{\mathrm{par}}\right] \\
& =\frac{3}{R_{\mathrm{w}}} \frac{\Phi_{\mathrm{w}}}{\bar{\rho}}\left[\left(\rho_{\mathrm{w}}-\rho_{\mathrm{pol}}\right)^{2}+\left(\rho_{\mathrm{pol}}-\rho_{\mathrm{par}}\right)^{2}(1+A)^{2 / 3}+\left(\rho_{\mathrm{par}}-\rho_{0}\right)^{2}(1+A+B)^{2 / 3}\right]
\end{aligned}
$$

with $A=\frac{\rho_{\mathrm{pol}}^{*}-\rho_{\mathrm{w}}}{\rho_{\mathrm{pol}}-\rho_{\mathrm{w}}} \frac{\Phi_{\mathrm{pol}}^{*}}{\Phi_{\mathrm{w}}}$ and $B=\Phi_{\mathrm{par}} / \Phi_{\mathrm{w}}$;

- Model A

$$
\begin{aligned}
16 \pi^{2} L_{\mathrm{P}} & =\frac{1}{\bar{\rho} V}\left[\left(\rho_{\mathrm{pol}}-\rho_{\mathrm{par}}\right)^{2} S_{\mathrm{pol}}+\left(\rho_{\mathrm{par}}-\rho_{0}\right)^{2} S_{\mathrm{par}}\right] \\
& =\frac{3}{R_{\mathrm{pol}}} \frac{\Phi_{\mathrm{pol}}}{\bar{\rho}}\left[\left(\rho_{\mathrm{pol}}-\rho_{\mathrm{par}}\right)^{2}+\left(\rho_{\mathrm{par}}-\rho_{0}\right)^{2}(1+C)^{2 / 3}\right],
\end{aligned}
$$

with $C=\frac{\rho_{\mathrm{pol}}-\rho_{\mathrm{w}}}{\rho_{\mathrm{pol}}^{*}-\rho_{\mathrm{w}}} \frac{\Phi_{\mathrm{par}}}{\Phi_{\mathrm{pol}}^{*}}$ 


\section{References}

[1] Ekwall, P., Mandell, L., Fontell, K., J. Colloid Interface Sci. 33 (1970) 215.

[2] Cabos, C. et Delord, P., J. Appl. Cryst. 12 (1979) 502.

[3] Jonsson, B., Doctoral Dissertation 1981, Lund, Sweden.

[4] Cabos, C., Delord, P., Rouvière, J., J. Appl. Cryst. 10 (1977) 3504.

Hendrikx, Y., Charvolin, J., J. Physique 42 (1981) 1427.

[5] Wong, M., Thomas, J. K., Gratzel, M., J. Am. Chem. Soc. 98 (1976) 2391.

Wong, M., Thomas, J. K., NowaK, T., J. Am. Chem. Soc. 99 (1977) 4730.

[6] Reiss-Husson, F., Luzzati, V., J. Phys. Chem. 68 (1964) 3504.

[7] GuINIER, A. et Fournet, G., Small-Angle Scattering of X-Rays (John Wiley and sons, New-York) 1955.

[8] Porod, G., Kolloid Z. 125 (1952) 51.

[9] Rouvière, J., Couret, J. M., Lindheimer, M., Dejardin, J. L., Marrony, R., J. Chim. Phys. 76 (1979) 289.

[10] Note that this result is different from the value found by Ekwall [1] $\left(v_{\mathrm{AOT}}=0.8789 \mathrm{ml} / \mathrm{mg}\right)$. The solvent here is p-xylene.

[11] Naudon, A., Caisso, J., J. Appl. Cryst. 7 (1974) 25.

[12] Day, R. A., Robinson, B. H., Clarke, J. H. R., Doherty, J. V., J. Chem. Soc., Faraday Trans 1 75 (1979) 132.

[13] Eicke, H. F., ReHAK, J., Helv. Chim. Acta 59 (1976) 2883.

[14] This hypothesis seems to be valid in the studied system AOT-water-heptane. It is not true when the solvent is decane [Kotlarchyc et al., J. Phys. Chem. 86 (1982) 3273]. The effect of oil on the structure of the reversed micelles will be published later. 